\title{
O ARGUMENTO DA ESTABILIDADE NO CONTRATUALISMO DE JOHN RAWLS
}

\author{
Lucas Petroni* \\ lucas.petroni@gmail.com
}

RESUMO Neste artigo, são rejeitadas duas teses relativamente aceitas a respeito do projeto filosófico tardio desenvolvido por John Rawls. A primeira tese afirma que o objetivo de obras como "O Liberalismo Politico" (1993; 1996) e "Justiça como Equidade: Uma Reformulação" (2001) seria o de revisar a natureza do argumento contratualista de Rawls. A segunda, por sua vez, afirma que a principal consequência dessa revisão teria sido certo recuo das implicações igualitárias de sua teoria da justiça original. Procurar-se-á rejeitar ambas as proposições mostrando que (i) "O Liberalismo Político" deve ser entendido como uma teoria acerca do uso legítimo do poder em uma sociedade democrática (e não como uma nova teoria da justiça), e (ii) que essa teoria da legitimidade possui consequências distributivas próprias, incompativeis com teorias liberais convencionais.

Palavras-chave Contratualismo, Igualitarismo, Legitimidade.

ABSTRACT The article aims to reject two interrelated theses on the philosophical project carried forward by the late John Rawls. The first thesis states that there is an important change in Rawls' late works such as "Political Liberalism" (1993; 1996) and "Justice as Fairness: A Restatement" (2001) regarding the nature of his theory. Particularly, this change would had brought about a reassessment of Rawls' contractualist argument. The second thesis claims that one of the most important consequences of such reassessment

* USP/Yale. Artigo recebido em 31/05/2016 e aprovado em 21/08/2016.

KRITERION, Belo Horizonte, nº 136, Abr./2017, p. 139-161 
is the retreat from strong egalitarian commitments, as they were present in Rawls'original theory of justice. The article rejects both theses, showing (i) that Political Liberalism can be understood as a theory about the legitimate uses of power in a democratic society (and not a new theory of justice) and (ii) that such new theory of legitimacy brings about distributive consequences by its own that sharply contrast with classical liberal theories.

Keywords Contractualism, Equalitarianism, Legitimacy.

Ao descrever os objetivos de "O Liberalismo Político" [LP], ${ }^{1}$ Bernard Williams afirma que,

[d]iferentemente daqueles [autores] que produziram grandes contribuições filosóficas, [Rawls] não se contentou com o papel de zelador de seu próprio sistema, consertando pequenos vazamentos, apresentando-o a novos visitantes e modernizando parte da fiação para se adequar aos novos tempos. Ao contrário, [Rawls] em alguma medida basicamente repensou todo o seu sistema [e] nos forneceu, na prática, uma nova interpretação de suas próprias ideias. ${ }^{2}$

Bernard Williams constata que se, por um lado, Rawls insistiu em manter uma argumentação moral contratualista após a publicação de TJ, por outro, procurou desenvolver uma nova concepção de contratualismo. Nessa nova formulação, prossegue Williams, "o Princípio de Diferença passa a assumir um papel distintamente secundário", em relação a outros problemas, como a questão da tolerância e das liberdades individuais em uma sociedade pluralista. ${ }^{3}$ Essa mesma interpretação é partilhada por Young. Segundo a autora, a principal mudança entre as duas obras seria a revisão da definição de conflito social. Enquanto em TJ a principal causa de conflitos sociais seria "um conflito de interesses individuais na busca por bens e recursos no intuito da realização dos respectivos planos de vida dos agentes", em LP Rawls teria reformulado a causa dos conflitos a partir "dos fatos do pluralismo cultural". ${ }^{4}$ Tal como

1 Seguindo a convenção do campo, utilizarei as seguintes abreviações para me referir às obras de John Rawls: "Uma Teoria da Justiça" [TJ], "Justiça como equidade: uma concepção política, não metafísica" [JEP], "O Liberalismo Político" [LP] e "Justiça como Equidade: Uma Reformulação" [JCE]. Nos casos das obras não traduzidas, as traduções utilizadas são de minha própria autoria.

3 Williams (op. cit., p. 4).

4 Young (1995, p. 186). 
Williams, Young afirma que a mudança entre as duas obras teria "enfraquecido a capacidade da teoria [da justiça rawlsiana] em dar sustentação para argumentos acerca de justiça econômica". 5

Não são apenas os críticos declarados do contratualismo rawlsiano quem compartilham a interpretação de que existe um recuo nas teses igualitárias em LP. Mesmo antigos aliados de Rawls também sustentam a tese de que as obras posteriores à $\mathrm{TJ}$ teriam alterado o núcleo de sua argumentação contratualista e, com isso, pondo em risco as consequências igualitárias de sua obra anterior. Para Okin, LP "abafou por completo a parte redistributiva de sua obra" . ${ }^{6}$ Já para Barry, algumas das implicações de LP nos obrigariam a concluir "pelo abandono do segundo princípio de justiça". ${ }^{7}$

Essa recepção das obras de Rawls posteriores à TJ permanece forte na filosofia política contemporânea. Gerald Gaus sustenta, por exemplo, que apenas um "discípulo particularmente devoto de Rawls" não reconhece que, "ao término de seu projeto sobre liberalismo político, a teoria da justiça já se encontrava em completa desordem [conceitual]". ${ }^{8}$ Seguindo essa interpretação, um importante manual de teoria política sustenta que poderíamos resumir a teoria da justiça de Rawls, após TJ, como "uma visão minimalista, restrita, protetora e negativa da cidadania liberal", uma concepção nascida do medo e do cálculo de interesses mais do que das exigências normativas do igualitarismo. ${ }^{9}$

A visão recebida do projeto rawlsiano é fundada em duas teses distintas, ainda que inter-relacionadas. A primeira delas afirma que o objetivo central das conferências que constituem LP, e da reapresentação da justiça como equidade em JCE, seria o de revisar o argumento contratualista adotado originalmente em TJ. Chamemos a primeira tese de (a) "revisão do contratualismo". Já a segunda proposição afirma que, tendo sido bem-sucedida ou não, essa tentativa de reinterpretação do contratualismo teve como resultado prático o recuo das pretensões igualitárias de sua concepção de justiça original, aproximando, com esse movimento, a justiça rawlsiana da doutrina liberal clássica. Chamemos essa tese interpretativa de (b) "abandono do igualitarismo".

(1993, p. 1010) representa, paradoxalmente, a ameaça mais importante ao próprio legado igualitário de Rawls. De fato, algumas das principais críticas contemporâneas ao igualitarismo têm como inspiração autodeclarada a ideia de liberalismo desenvolvido por Rawls em LP (ver, por exemplo, os trabalhos de Tomasi, 2012, e Gaus, 2016). Contudo, como procurarei defender neste trabalho, críticas como essas partem de uma má compreensão dos argumentos apresentados em LP.

8 Gaus (2016, p. 5).

9 Vincent (2004, p. 164). 
A despeito de sua popularidade, acredito que ambas as teses estejam erradas. O objetivo deste trabalho é mostrar o que justifica essa dupla recusa. Em primeiro lugar, procurarei argumentar que LP realiza uma importante mudança do objeto da teoria contratualista rawlsiana e não dos objetivos do argumento moral contratualista. Em seus trabalhos posteriores à TJ, Rawls reconheceu o problema da legitimidade do exercício da coerção coletiva como um problema de primeira ordem para qualquer teoria da justiça (inclusive para a sua própria). Isso não significa, evidentemente, que Rawls não tenha revisto argumentos presentes em TJ à luz de críticas feitas a sua concepção de justiça. ${ }^{10}$ Significa apenas - mas esse é um ponto importante - que LP é perfeitamente compatível com o argumento moral rawlsiano, seja em sua fundamentação contratualista, seja com as demandas da igualdade distributiva.

Ainda que normalmente encontradas em conjunto, (a) e (b) são logicamente distintas entre si, na medida em que uma não implica necessariamente a outra. ${ }^{11}$ Isso significa que, em segundo lugar, precisamos responder se a teoria da legitimidade rawlsiana entra em conflito ou não com o ímpeto igualitário original de sua obra. Contra a tese (b) pretendo mostrar que, por si só, a teoria da legitimidade rawlsiana possui consequências distributivas nada desprezíveis para a constituição política de sociedades democráticas. Ao demandar requisitos distributivos como uma condição de legitimidade (e não apenas de justiça) das principais instituições políticas, a teoria da legitimidade rawlsiana não apenas é igualitária como é francamente contrária ao liberalismo clássico. Uma sociedade que não é capaz de garantir, por exemplo, um patamar mínimo de segurança social aos seus cidadãos e cidadãs não é apenas injusta do ponto de vista distributivo - argumento que poucos poderiam rejeitar -, mas caracteriza também um tipo ilegítimo de exercício da autoridade política.

Na verdade, ao mudar sua preocupação filosófica de uma teoria da justiça distributiva para uma teoria da legitimidade, a obra tardia de Rawls procurou expandir os debates filosóficos estabelecidos no campo das teorias da justiça para outros temas tradicionais da filosofia política, tais como os conceitos de legitimidade, tolerância e obediência, ou o papel de instituições políticas fundamentais em uma democracia, como a revisão constitucional de leis e o voto.

10 Entre as principais reformulações de sua teoria original estão: (i) a rejeição da proposição segundo a qual teorias da justiça são uma parte da teoria da decisão (JCE, p. 82), (ii) uma concepção sociológica, e não mais essencialista, de "bens sociais primários" (JCE, pp. 57-58, e LP, V §2) e (iii) uma ênfase maior no valor equitativo de algumas liberdades fundamentais, como as liberdades políticas (JCE, pp. 148-150, e LP, VIII §12; contudo ver a seção 36 de TJ).

11 Na prática, contudo, (a) e (b) tendem a andar juntas uma vez que uma tese reforça a validade da outra: porque Rawls revisou seu argumento contratualista, então a teoria se tornou menos igualitária em termos distributivos. 
Discussões essas muitas vezes ignoradas pelos debates focados exclusivamente nas questões da justiça. Significa, em uma palavra, valorizar uma concepção política de igualitarismo.

\section{O igualitarismo de Uma Teoria da Justiça}

De modo muito geral, podemos afirmar que em TJ John Rawls defende a tese segundo a qual nós, cidadãos e cidadãs de sociedades democráticas, devemos avaliar e, quando necessário, transformar a estrutura social de nossas sociedades de acordo com critérios igualitários de justiça justificados por meio de um argumento moral contratualista. ${ }^{12} \mathrm{~A}$ ideia central do contratualismo é que, de um ponto de vista moral, o que torna algo certo ou errado é a sua concordância, ou não, com princípios que seriam o objeto de um acordo, sob as circunstâncias apropriadas, entre todos os membros da comunidade moral relevante. No caso de Rawls, os princípios de justiça são o resultado de um processo hipotético de deliberação moral entre agentes morais livres e iguais que teriam por motivação conceber e aplicar critérios de justiça responsáveis por organizarem o arranjo institucional básico da sociedade em que vivem. A tarefa prática de uma concepção de justiça, tal como formulada por Rawls, é fornecer princípios públicos de justiça a partir dos quais podemos avaliar a distribuição (justa) de recursos sociais em uma determinada sociedade. Recursos esses que, nas palavras de Rawls, as pessoas "precisam em seu status de cidadãos livres e iguais e de membros normais e plenamente cooperativos da sociedade durante suas vidas". ${ }^{13}$ Uma sociedade justa no sentido rawlsiano deve ser descrita como uma sociedade na qual uma concepção comum de justiça regula as principais instituições sociais responsáveis pela distribuição dos benefícios e encargos produzidos pela cooperação social.

Como sabemos, o resultado substantivo de TJ são dois princípios de justiça que, juntos, constituem aquilo que Rawls denomina de "justiça como equidade". ${ }^{14}$

12 Ver Scanlon (2003) e Barry (1989) para as diferentes modalidades das teorias contratualistas. Neste trabalho, denominarei de "contratualista" apenas a teoria rawlsiana o que, evidentemente, implica uma grande simplificação em relação aos diferentes tipos de contratualismo.

13 TJ (p. xxxviii).

14 O Primeiro Princípio exige que os direitos e liberdades pessoais sejam distribuídos de modo estritamente igual entre todas as pessoas que atendam, ao menos potencialmente, às exigências de uma agência moral autônoma. O segundo princípio, composto por duas partes, exige que qualquer desigualdade na distribuição de poder, renda e riqueza individual esteja atrelada a cargos ou posições sociais abertas a todos (Princípio da Igualdade Efetiva de Oportunidades) e que qualquer desvio de uma distribuição estritamente igual de recursos econômicos será justo se, e apenas se, tal diferença for justificada tendo como objetivo o máximo benefício dos membros menos beneficiados pela cooperação social (Princípio da Diferença). A versão final dos dois princípios, adotada neste trabalho, pode ser encontrada em LP (p. 6) e JCE (pp. 42-43). 
A concepção de justiça rawlsiana faz pelo menos duas afirmações fortes ante as desigualdades socioeconômicas comumente encontradas nas sociedades contemporâneas. Em primeiro lugar, que qualquer forma de desigualdade distributiva, seja de direitos, oportunidade ou recursos necessários à sua plena efetivação, deve ser justificada publicamente entre iguais. Ou seja, que a igualdade dos bens primários é, por assim dizer, o benchmark distributivo em sistema cooperativo composto por iguais, de tal forma que não existem desigualdades distributivas imunes à demanda por justificação moral. ${ }^{15} \mathrm{~A}$ segunda implicação igualitária é que a única maneira de justificar desigualdades de poder e recursos materiais, de um ponto de vista moral, é demonstrando que tais desvios da igualdade estrita são compatíveis com uma concepção efetiva da igualdade de oportunidades e que, além disso, desigualdades de renda e riqueza beneficiarão maximamente as piores posições sociais (com isso, privilegiando mais os membros menos favorecidos pela cooperação social).

É preciso atentarmos para o fato de que não apenas grande parte das implicações igualitárias da justiça rawlsiana estão longe de serem atendidas mesmo entre as sociedades mais igualitárias que conhecemos, como também que não poderiam ser plenamente satisfeitas sem a transformação radical das principais instituições sociais de uma democracia liberal, como o Estado, o governo representativo, a família e, principalmente, o mercado. Nunca é demais lembrar que, para Rawls, os dois únicos sistemas socioeconômicos ideais compatíveis com as implicações igualitárias da justiça como equidade são ou (i) uma forma democrática de socialismo, na qual os meios de produção e as principais decisões produtivas da sociedade são determinadas democraticamente pela força de trabalho, ou (ii) uma democracia de cidadãos proprietários, na qual as principais instituições econômicas trabalhariam para constantemente dispersar a propriedade de riqueza privada (e consequentemente de capital produtivo) garantindo que todos os cidadãos e cidadãs tenham acesso à propriedade. ${ }^{16}$

Existem inúmeras formas de reconstruir os argumentos de TJ. O resumo apresentado está longe de fazer justiça à complexidade dos argumentos rawlsianos. ${ }^{17}$ Contudo, para efeitos deste artigo, assumirei que esse esboço

15 TJ (p. 75).

16 Rawls apresenta esses dois modelos em TJ (pp. 337-341) e define uma democracia de cidadãos proprietários em JCE (pp. 135-140).

17 Ao formular a concepção de justiça como equidade do modo como estou propondo, procuro dar ênfase àquilo que filósofos como Cohen (1986, p. 729) e Vita (2009, p. 64) identificam como a grande contribuição teórica de Rawls para o igualitarismo contemporâneo: a justificação de dois princípios de justiça a partir de um mesmo argumento moral, com base no qual podemos lidar, ao mesmo tempo, com demandas normalmente associadas às bases da cidadania democrática e com demandas vinculadas à igualdade socioeconômica. 
representa de modo mais ou menos fiel os objetivos do projeto igualitário presente em TJ e que, também, ele está correto do ponto de vista moral. Ou seja, que o conjunto de argumentos oferecidos em TJ são suficientes para aceitarmos os dois princípios de justiça como a concepção pública de justiça mais apropriada para uma sociedade democrática. Caso as teses da revisão contratualista e do abandono do igualitarismo estejam corretas, então somos obrigados a aceitar que, direta ou indiretamente, Rawls teria rejeitado parte dessas consequências em seus trabalhos pós-TJ.

\section{O Liberalismo Político e o uso opressivo da filosofia política}

Em que medida LP marca uma diferença nesse projeto? Como vimos acima, a visão recebida de LP insiste na tese de uma reformulação significativa entre as duas obras. Essa conclusão é amplamente corroborada pela própria autoexplicação encontrada nos trabalhos posteriores à TJ. Rawls explica a mudança na formulação de sua concepção de justiça original nos seguintes termos:

em uma democracia constitucional a concepção pública de justiça deve ser, tanto quanto possível, independente de doutrinas filosóficas e religiosas controversas. Desse modo, para formular essa concepção, aplicamos o princípio de tolerância à própria filosofia: a concepção pública de justiça deve de ser política, não metafísica [...] Algo que falhei em explicar em Uma Teoria da Justiça, ou falhei em enfatizar o suficiente, é que a justiça como equidade pretende ser uma concepção política de justiça. ${ }^{18}$

Ou seja, a principal mudança entre as duas formulações é a reformulação da justiça como equidade como uma concepção estritamente política de justiça, com o objetivo de ser ("tanto quanto possível") compatível com as exigências normativas de uma democracia constitucional.

Rawls passou a reconhecer que qualquer concepção de justiça (seja ela a justiça como equidade ou não) precisa ser compatível com a diversidade natural de doutrinas morais, religiosas ou filosóficas encontradas na vida política dessas sociedades. Rawls denomina essa exigência como o reconhecimento do "fato do pluralismo razoável” entre diferentes concepções de bem. ${ }^{19}$ Em uma sociedade organizada a partir de instituições livres, tais como a igualdade de liberdades individuais e liberdade de expressão e associação, uma pluralidade de doutrinas morais, religiosas e seculares, serão endossadas espontaneamente por seus 
cidadãos e cidadãs, exercendo seus plenos poderes políticos e legais. Isto é, não há nada que as instituições políticas possam fazer legitimamente para eliminar essa condição fundamental da democracia, na medida em que o pluralismo moral seria "o resultado esperado do exercício da razão humana sob a estrutura de instituições livres de um regime democrático constitucional". ${ }^{20} \mathrm{O}$ pluralismo de valores e a diversidade de estilos de vida são características inalienáveis da razão humana em liberdade. Essa pluralidade é, ao mesmo tempo, conflitiva e "razoável". Isto é, podemos esperar que um grupo de doutrinas sejam, ao mesmo tempo, contraditórias entre si e compatíveis com as instituições políticas de uma democracia, incluindo as próprias garantias da liberdade individual. Apenas o uso sistemático e opressivo da coerção estatal poderia suprimir esse conflito, obrigando, por exemplo, todos os cidadãos e cidadãs a endossarem uma mesma doutrina moral a respeito da natureza da vida em sociedade ou da felicidade humana individual.

O reconhecimento do fato do pluralismo razoável coloca uma pergunta crucial para o contratualismo rawlsiano: como é possível esperarmos que uma mesma concepção de justiça (e. g. a justiça como equidade) seja assumida por todos como a concepção pública comum para a avaliação das instituições sociais e, ao mesmo tempo, não opressiva? Ao reconhecer o fato do pluralismo moral em uma sociedade democrática, Rawls está reconhecendo, pelo mesmo argumento, que mesmo uma concepção de justiça fundada em princípios morais corretos possa ser, ela própria, uma forma de opressão contra as múltiplas e contraditórias filiações afetivas, identitárias e morais necessariamente encontradas em uma sociedade democrática.

Colocado dessa forma, não é difícil entender por que LP tenha gerado a suspeita de que existe uma mudança substantiva na natureza da teoria da justiça rawlsiana. Dada a magnitude de colocações como essa e a estrutura intrincada (para não dizer, em alguns pontos, barroca) de LP, é natural concluirmos que algo importante mudou. Porém, é exatamente difícil precisar o que mudou exatamente.

$\mathrm{O}$ restante deste artigo será dedicado a demonstrar que a mudança entre TJ e LP não é uma mudança a respeito da natureza do argumento moral, mas sim uma mudança de objeto. Se TJ procura oferecer uma concepção de justiça, o esforço contido em LP - seja ele bem-sucedido ou não - deve ser entendido como uma

20 LP (p. xvii). O emprego do termo "condição fundamental do pluralismo", ao invés do tradicional "problema do pluralismo", é importante para o argumento rawlsiano na medida em que, a rigor, o conflito de valores razoáveis não se trata de algo a ser erradicado pela filosofia. Agradeço o comentário de Alexandre Franco de Sá sobre esse ponto. 
tentativa de construir uma teoria da legitimidade do exercício do poder político entre iguais em reivindicações morais. Tal teoria, denominada por Rawls como liberalismo político, é, ao mesmo tempo, compatível com as exigências do pluralismo de valores morais típicos de uma sociedade democrática e coerente com as demandas igualitárias da justiça como equidade. A melhor forma de entendermos por que uma teoria da legitimidade passou a ser necessária à justiça rawlsiana (e ao contratualismo como um todo) é reconstruindo o problema da estabilidade de concepções de justiça em argumentos contratualistas.

\section{O problema da estabilidade}

Segundo Rawls, o LP deve ser entendido "como um esforço para resolver um grave problema interno à justiça como equidade", a saber, o de que "a interpretação da estabilidade na parte III de Teoria não é coerente com a visão do todo". ${ }^{21}$ Essa afirmação é importante e merece ser analisada com mais atenção do que normalmente tem sido despertada. Com ela, Rawls compromete-se explicitamente com duas proposições importantes a respeito de seu projeto filosófico. Em primeiro lugar, que o "grave problema interno" a ser solucionado por LP é associado ao que Rawls havia denominado em TJ como o problema da estabilidade de uma concepção de justiça. ${ }^{22}$ Em segundo, que a nova formulação da justiça como equidade, enquanto uma concepção compatível com os critérios da legitimidade democrática, é perfeitamente consistente com a estrutura argumentativa e com as implicações da justiça como equidade. Como afirma Rawls: "[d]e resto, [as] conferências [de LP] consideram que a estrutura e o conteúdo de [TJ] permanecem substancialmente os mesmos".23

21 LP (p. xvi).

22 Um trabalho excelente, e muito mais detalhados do que os argumentos aqui propostos, sobre o problema da estabilidade no contratualismo rawlsiano, é Weithman (2011). O que identifico aqui como visão recebida do LP possui fortes similaridades com o que Weithman denomina de "the public basis view". Contudo, discordo parcialmente da interpretação de Weithman na medida em que ela não leva em consideração as críticas do liberalismo agonístico à justiça como equidade. Do fato de que as críticas comunitaristas não servem para entender o problema da estabilidade - algo que estamos de completo acordo - não se segue que não existam outras críticas importantes exteriores à justiça como equidade. De modo muito resumido, o equívoco da interpretação da mudança fundada na chamada crítica comunitarista repousa em uma má compreensão do problema do pluralismo moral. Reconhecer a validade do pluralismo moral enquanto condição natural da vida em sociedade implica rejeitar, como moralmente ilegítima, a possibilidade comunitarista de que uma doutrina moral abrangente possa ser partilhada por todos os membros de uma mesma sociedade política. Se quisermos encontrar algum "culpado" pela reformulação do argumento, então os principais suspeitos devem ser procurados no campo das teorias liberais. Em especial, nas objeções presentes em uma variedade cética de liberalismo, defendida por autores como Isaiah Berlin, Bernard Williams e Stuart Hampshire, todos eles teóricos do conflito irredutível de valores morais. Agradeço a Marcos Fanton por ter me levado a enfrentar esse ponto.

23 LP (p. xvi), ênfases acrescidas. 
O problema da estabilidade é o nome dado por Rawls para uma etapa argumentativa presente em seu argumento contratualista, mas que, por meio de outros nomes, é encontrado em praticamente toda tradição contratualista. ${ }^{24}$ Teorias contratualistas são estruturadas a partir de duas etapas argumentativas interdependentes: a construção de uma situação original de escolha nas quais as partes envolvidas procuram comparar e conceber princípios morais à luz de interesses e valores específicos, e o teste dos termos acordados em relação às exigências impostas sobre aqueles que terão de cumpri-las ao longo de suas vidas. Seguindo a útil formulação de Jeremy Waldron, podemos dizer que, em seu sentido moral, um contrato deve ser entendido como o resultado de um contexto de escolha e de um contexto de compromisso. ${ }^{25}$

Comecemos com uma analogia com o conceito intuitivo de contrato. Os contextos da escolha e do compromisso fazem parte de qualquer acordo válido. De um ponto de vista moral (mas não necessariamente legal), as duas etapas representam os dois tipos de argumentos que podem invalidar um contrato. $\mathrm{O}$ tipo de argumento mais direto capaz de anular um acordo é quando seus termos são obtidos por meio de coerção ou fraude sobre uma das partes. Tendemos a dizer, nesse caso, que o contrato é injusto. Contudo, existe um segundo modo por meio do qual os termos podem ser invalidados (novamente, de um ponto de vista moral). Caso existam bons motivos para suspeitar que os termos do acordo, por mais consensuais e justos que possam vir a ser, não serão facilmente cumpridos pelas partes contratantes em contextos normais de cooperação, somos justificadamente levados a concluir que os termos não são factíveis do ponto de vista do compromisso contratual e que, portanto, sua validade moral é nula. Isso pode acontecer quando, por exemplo, os termos acordados não estão suficientemente claros, ou quando as circunstâncias normais de aplicação não são de conhecimento geral, ou ainda a sua aplicação pode gerar, no longo prazo, consequências adversas. Em todos esses casos, é perfeitamente plausível reivindicarmos que o acordo é inválido e, sendo assim, querer obrigar a sua anuência pode ter consequências opressivas. $\mathrm{O}$ problema no segundo tipo de argumento não é exatamente de injustiça, mas sim da estabilidade do acordo: os agentes terão fortes incentivos para fugir às suas obrigações. Dadas as instituições como poderiam ser e os homens e mulheres como normalmente são, então temos boas razões para descartar a escolha dos termos acordados como irrealistas e uma nova escolha se faz necessária. ${ }^{26}$

24 Ver Cohen (1986) para o caso de Rousseau, e Vita (2007, pp. 120-129), para teorias hobbesianas.

25 Waldron (1986, pp. 26-27).

26 A validade desse argumento depende, é claro, da dificuldade de encontrar outras formas de tecnologia social e exigências motivacionais mais árduas do que as que normalmente aceitamos. Como afirma Rawls 
De um modo mais elaborado, teorias contratualistas seguem o mesmo raciocínio intuitivo apresentado acima. Argumentos contratualistas precisam ser capazes de nos oferecer não apenas quais princípios determinados agentes morais escolheriam em um contexto imparcial de escolha, mas também com quais princípios tais agentes estariam preparados para se comprometerem ao longo de suas vidas. As razões em jogo em cada um dos contextos são muitas vezes conflitantes entre si. Ilustrações desse tipo de conflito são fartamente encontradas nas ciências sociais quando precisam explicar, por exemplo, a lógica de funcionamento de bens públicos. ${ }^{27}$

Um bem público é mantido com sucesso entre agentes racionais quando cada uma das partes envolvidas desenvolve um plano de ação consistente com todos os demais. Tomemos como exemplo de provisão de bem público a criação e manutenção de uma área comum arborizada entre os membros de um bairro na cidade de uma metrópole brasileira. É razoável esperarmos que todos os moradores tenham interesse em tornar o bairro uma região mais verde e arborizada. Ou seja, enquanto contratantes, todos possuem motivos para aderirem a sua criação. Contudo, dadas as exigências de cooperação impostas pela manutenção da área - limpeza e preservação, perda de espaço para os carros etc. - os compromissos trarão custos diferentes para moradores diferentes. Por unanimidade, todos preferem que a área seja criada, mas existirão circunstâncias nas quais os custos de sua provisão serão diferenciados e, caso excessivamente oneroso sobre alguns, farão com que os moradores optem por não aderir ao contrato. A razão para a não adesão é fundada na falta de equidade dos termos do acordo: a necessidade de comprometimentos unilaterais e uma distribuição desigual de deveres tendem a fomentar comportamentos de tipo "carona", nos quais os agentes se beneficiam da criação do acordo, mas não estão dispostos a fazerem a sua parte caso a omissão passe relativamente despercebida. Notemos que, nesse caso, a não adesão ao bem público não é motivada necessariamente por egoísmo, mas sim pela sensação de injustiça imposta por eventuais caronas. Mesmo um punhado de moradores completamente altruístas não conseguirão, sozinhos, assegurar as condições apropriadas para a criação da área verde.

em relação a esse ponto: "ou nossas concepções de justiça são justificadas pelas condições da nossa vida conforme as conhecemos ou não serão [justificadas] de modo algum" (TJ, p. 560). Para autores como Cohen, essa "concessão aos fatos" seria o principal problema das teorias contratualistas. Ver, Cohen (2003, p. 213, 235-236).

27 Para uma definição padrão de equilíbrio e algumas ilustrações desse tipo de situações cotidianas, ver Elster, 1989 (pp. 101-102). O problema da estabilidade no contratualismo rawlsiano equivale ao que Elster denomina problemas de cooperação, e não problemas de coordenação. 
Ambas as etapas do argumento contratual sempre estiveram presentes no contratualismo rawlsiano. ${ }^{28} \mathrm{O}$ contexto de escolha corresponde ao argumento da Posição Original, no qual as partes do contrato social contam com os mesmos poderes e direitos na escolha de princípios que regularão a estrutura básica da sociedade em que vivem. ${ }^{29}$ Rawls constrói a posição original de escolha de princípios a partir de restrições cognitivas impostas a agentes racionais, procurando estabelecer termos comuns para a distribuição de recursos sociais. A função normativa do "véu de ignorância" é garantir um contexto de imparcialidade moral na escolha dos princípios e suas restrições correspondem ao conjunto de fatores moralmente arbitrários em nossas vidas, como raça, gênero, classe e produtividade individual, que, não obstante se encontrem além de nossas escolhas pessoais, determinam em grande medida a realização de nossos planos de vida. ${ }^{30}$

O contexto do compromisso corresponde, justamente, ao problema da estabilidade. As diferentes concepções de justiça ajuizadas no contexto de imparcialidade precisam, ao mesmo tempo, ser testadas em relação aos ônus de sua aplicação em condições normais de cooperação. Em TJ, Rawls oferecenos ao menos três argumentos importantes em favor da estabilidade contratual da justiça como equidade: ${ }^{31}$ (i) o ônus do compromisso relativo das diferentes concepções de justiça, ${ }^{32}$ (ii) a compatibilidade das exigências da justiça com a psicologia moral humana ${ }^{33}$ e, finalmente, (iii) a congruência entre concepções de bem e as exigências da justiça. ${ }^{34}$ Enquanto (i) é um argumento que procura mostrar a superioridade relativa da justiça como equidade sobre as demais concepções de justiça, (ii) e (iii) impõem condições absolutas (i. e., não relativas) ao acordo moral. Em TJ, o caso paradigmático de estabilidade tratado é o da psicologia moral. Na parte III de TJ, Rawls oferece uma longa e sinuosa discussão a respeito dos pressupostos psicológicos necessários para garantir que os princípios de justiça possam ser sustentados no longo prazo entre pessoas livres e iguais. ${ }^{35}$ Rawls enfatiza, por exemplo, nossa capacidade de expandirmos os laços de reciprocidade mesmo entre estranhos ao internalizarmos a reprodução

28 TJ (p. 176 e pp. 612-615) e JCE (pp. 88-89).

29 TJ (cap. III).

30 É sempre bom relembrar que o resultado final do contrato é justificado a partir de uma motivação moral substantiva, i. e., o desejo de justificar critérios públicos de cooperação social entre pessoas livres e iguais, e não pela razão instrumental de indivíduos autointeressados. A melhor defesa dessa interpretação ainda me parece ser a de Darwall (1976).

31 Rawls elenca os argumentos em TJ (§ 86).

32 TJ (§ 76). Trata-se do argumento desenvolvido por Rawls contra teorias utilitaristas com base no "ônus do compromisso" (strains of commitment no original). A excelente tradução foi proposta por Flávio Reis.

$33 \mathrm{TJ}(\S 75)$

$34 \mathrm{TJ}(\S 86)$.

35 Cf. TJ (§ 70-72); JCE (pp. 195-196). 
de arranjos coletivos equitativos. A lógica do argumento é simples: caso não fôssemos capazes (enquanto agentes morais de carne e osso) de desenvolver um senso de justiça ao longo de nossas vidas, então a única maneira de garantir que não iríamos violar as exigências impostas pelos princípios em situações desfavoráveis aos nossos interesses pessoais seria por meio do medo da coerção. ${ }^{36}$

Contudo, o argumento que nos interessa neste artigo é (iii), também conhecido como o argumento da congruência entre concepções de bem e as exigências da justiça. Aceitemos então que, além de livres e iguais, os agentes morais sejam dotados de um senso básico de justiça por meio do qual sejam capazes de entender e aplicar as exigências impostas pela justiça. Não é difícil imaginar cenários nos quais as demandas públicas da justiça e as filiações morais particulares dos agentes entrarão em conflito. Tomemos como exemplo a instituição da taxação (extremamente) progressiva de renda demandada pelo segundo princípio sobre os mais favorecidos pela cooperação social. Mesmo não tendo contato direto com aqueles beneficiados pela redistribuição, espera-se que, por razão de justiça, os mais favorecidos arquem com o ônus de arranjos distributivos justos mesmo quando essas exigências entrem em conflito com suas perspectivas de boa vida. Do ponto de vista justiça como equidade, justiça e felicidade pessoal precisam ser congruentes, e não equivalentes.

Como garantir, então, que as concepções de bem sejam compatíveis com os princípios de justiça quando entrarem em conflito? $\mathrm{O}$ argumento a favor da congruência originalmente apresentado em TJ sustenta que agir justamente, isto é, a partir dos princípios escolhidos pela posição original, é algo que, enquanto agentes racionais, tendemos a buscar, na medida em que desejamos expressar "nossa natureza de pessoas morais livres". ${ }^{37}$ Rawls assume uma teoria abrangente sobre a agência moral humana, segundo a qual, caso queiramos realizar nossa verdadeira natureza moral, não teríamos, de fato, outra alternativa a não ser planejar nossas vidas a partir do senso de justiça. Na verdade, os desejos de agir justamente e de ter uma vida feliz acabariam sendo "praticamente o mesmo desejo", isto é, duas maneiras diferentes de expressar uma mesma verdade moral acerca do conceito de pessoa. ${ }^{38}$

Contudo, uma vez reconhecido o fato do pluralismo razoável, precisamos rejeitar, ou pelo menos impor restrições consideráveis, a esse raciocínio. Podemos ilustrar o problema por meio do tipo de demanda normalmente imposta por doutrinas religiosas aos seus fiéis. Do ponto de vista do fiel, a adesão aos

36 Essa é, justamente, a solução hobbesiana para o problema da estabilidade.

37 TJ (p. 705).

38 TJ (p. 705). 
fundamentos teológicos de sua doutrina religiosa não é necessariamente o resultado de uma escolha autônoma feita por um sujeito racional. Ela pode ser interpretada como o reconhecimento de uma verdade moral exterior à vontade racional humana e, portanto, "heterônoma" do ponto de vista da autonomia racional. O mesmo vale para uma variedade de modos de vida compatíveis com as exigências de uma sociedade democrática, mas que rejeitam a autonomia individual como um valor. Se, por um lado, certamente, a justiça exige que agentes morais reconheçam todas as pessoas como livres e iguais em suas ações, por outro, nem todos os adeptos de doutrinas morais abrangentes razoáveis aceitarão que o motivo para isso, tal como Rawls procurou defender em TJ, seja a expressão da verdadeira concepção de pessoa. Talvez a razão para a congruência possa ser encontrada diretamente nos fundamentos teológicos das doutrinas, ou simplesmente elas permitem que seus adeptos estabeleçam uma divisão entre os deveres mundanos e extramundanos. Seja como for, do ponto de vista do cidadão, as demandas da justiça não são autônomas.

Quando reconhecemos o fato do pluralismo como condição normal de cooperação, então somos obrigados a aceitar que existem muitas (mas certamente não infinitas) formas distintas de obtermos a congruência entre justiça e felicidade humana em uma sociedade plenamente organizada pelos princípios de justiça.

\section{Uma concepção política de justiça}

Se a interpretação que está sendo proposta estiver correta, então a diferença entre TJ e LP encontra-se nos argumentos elencados a favor da justiça como equidade na etapa do contexto do compromisso da argumentação contratualista. Mais precisamente, a diferença entre as duas obras está no reconhecimento da falta de um argumento: Rawls reconhece a incoerência entre, de um lado, a expectativa de congruência entre concepções de bem e as exigências da justiça e, de outro, as exigências impostas pelo pluralismo moral.

Concepções de justiça precisam ser estáveis em relação à motivação moral esperada de cidadãos e cidadãs democráticos(as), os quais são socializados e formam suas expectativas de vida tendo como pano de fundo o fato do pluralismo irreconciliável entre diferentes concepções de bem. LP oferece como resposta a esse problema uma teoria a respeito da legitimidade do exercício do poder político.

O raciocínio rawlsiano é simples: em uma sociedade democrática, na qual cidadãos iguais em direitos e liberdades precisam exercer o poder coletivo uns sobre os outros, certas restrições ao seu exercício são necessárias. A mais importante delas é aquilo que Rawls denomina como o "princípio liberal de 
legitimidade", ${ }^{39}$ segundo o qual um poder político é legítimo apenas "se for exercido de acordo com uma constituição política [...] a qual seus elementos essenciais possam ser aceitos por todos os cidadãos [...] no uso das faculdades racionais comuns a todos" ${ }^{40}$ Ou seja, o uso da coerção política é legítimo se, e somente se, ele puder respeitar as formas razoáveis de desentendimento profundo que encontramos em uma democracia pluralista. No limite, ainda que possamos demonstrar que uma teoria moral (em sentido abrangente) esteja correta, mesmo assim ela estaria submetida ao princípio da tolerância democrática.

Os critérios públicos de legitimidade são a única maneira de garantir que iguais em reinvindicação do poder respeitem a cidadania alheia nas decisões políticas centrais de uma sociedade democrática. Isso significa que a única forma de garantir que a justiça como equidade evite o uso opressivo da filosofia contra o pluralismo é demonstrando que ela pode ser formulada como uma concepção política (e não ética ou religiosa) de justiça "que se sustente por si própria" ${ }^{41}$ Ou seja, cuja congruência possa ser sustentada a partir de uma noção meramente política de autonomia.

Em linhas gerais, Rawls identifica três aspectos centrais que caracterizariam uma concepção política (não metafísica) de justiça: ${ }^{42}$ (i) uma concepção política é formulada para o domínio do político de uma sociedade; (ii) uma concepção política aplica-se à estrutura básica da sociedade e não às interações pessoais de agentes morais e, finalmente, (iii) uma concepção política de justiça se contrapõe às concepções abrangentes de bem que constituem a pluralidade de modos de vida em uma democracia constitucional.

Antes de analisar as exigências que cada um desses aspectos impõe a uma concepção de justiça, é importante desfazer uma forma comum de incompreensão relacionada ao uso do adjetivo "político" no argumento rawlsiano. Uma concepção política no sentido de LP não se opõe a uma concepção moral de justiça. Concordemos ou não com a proposta de Rawls, é razoavelmente evidente que a objetivo de fundamentar os termos da cooperação social em princípios morais permanece inalterada. Ela não se tornaria política porque, por exemplo, procura justificar suas exigências em interesses e valores contingentes - tal como um compromisso minimamente estável entre diferentes forças sociais existentes

39 Ver adiante, contudo, o significado de "liberal". A outra restrição desenvolvida em LP é a ideia de razão pública (cf. LP C VI).

40 JCE, p. 41. Ver também LP (C VI, § 4).

41 LP (p. 165) e JCE (p. 187).

42 Os três pontos são uma tentativa de reconstruir os argumentos apresentados em diferentes partes de LP. A discussão detalhada de cada um dos aspectos pode ser encontrada, respectivamente, em: (1) JEP (p. 390), JCE (§ 54), LP (p. 12); (2) JEP (pp. 395-396), JCE (§ 15), LP (pp. 13-14); e (3) JEP (p. 394-395), JCE (§ 57), LP (pp. 14, - 15). 
em uma sociedade. Tal sentido de político, como um modus vivendi, está mais próximo da resposta ao pluralismo moral oferecido pelo chamado liberalismo do medo. ${ }^{43}$ Tampouco o adjetivo "político" pode ser entendido (apenas) como o resultado da autointerpretação de uma cultura política específica. Essa proposta estaria mais próxima às teorias liberais de Michel Walzer e Richard Rorty. ${ }^{44}$ Se por moralidade entendemos a tarefa de formular princípios normativos para a conduta humana, concepções políticas de justiça são tão morais quanto concepções abrangentes. ${ }^{45}$ A diferença entre os dois tipos de concepção de justiça não se encontra no quantum de moralidade que cada uma delas exige, nem mesmo se são formuladas por meio de um vocabulário estritamente moral ou não, mas sim no modus como as formulamos, definindo limites e fundamentos normativos próprios.

Em primeiro lugar, uma concepção política de justiça se aplica ao "domínio do político" na medida em que tem por objetivo uma esfera específica da cooperação social. Existem dois modos distintos de entendermos essa afirmação e os dois fazem parte das exigências tal como formuladas por Rawls. O primeiro modo está relacionado com o próprio papel da filosofia política em uma sociedade democrática, o segundo, com o escopo de sua aplicação. Como afirma Rawls, não devemos conceber a filosofia política como uma espécie de filosofia moral aplicada aos problemas específicos da vida política. ${ }^{46}$ Essa forma "aplicada" de entender a filosofia política é defendida, por exemplo, por Robert Nozick ao afirmar que a filosofia moral "define [...] as fronteiras da filosofia política. O que as pessoas podem ou não fazer umas às outras limita o que elas podem ou não fazer por meio do Estado". ${ }^{47}$ Isto é, princípios normativos são estabelecidos por argumentos morais independentes e, posteriormente, suas consequências são estendidas para a regulação das instituições coercitivas de uma sociedade. Em contraste com essa visão, uma concepção política de justiça no sentido rawlsiano reconhece que as relações políticas entre iguais constituem uma forma específica de ação, regida por princípios normativos próprios, e que esses princípios podem exigir inclusive uma modificação nos modos apropriados de argumentação filosófica entre cidadãos na esfera pública.

Em segundo lugar, o domínio do político reivindica, de um ponto de vista sociológico, que relações políticas diferem de outras formas possíveis de associação, como as esferas associativas, fundadas no princípio do consentimento, 
e as esferas familiares, fundadas em valores afetivos. ${ }^{48}$ Relações políticas constituem um objeto privilegiado para a justiça na medida em que são expressas no mais das vezes por meio de regras de conduta fundada no exercício da coerção coletiva. Mesmo quando pacíficas e tomadas por meio de procedimentos legítimos, decisões políticas sempre possuem implicações coercitivas (diretas ou indiretas) em sociedades complexas. Qualquer princípio moral que se pretenda um guia dessas decisões precisa levar a sério a natureza específica dessa forma de relação.

Finalmente, se uma concepção de justiça política é concebida tendo como objeto o domínio do político, isso significa que ela pode reconhecer o fato do pluralismo razoável e, portanto, seus princípios podem ser, em tese, compatíveis com o status político de cidadãos e cidadãs livres e iguais. Isto é, caso aceitemos (1) e (2), precisamos aceitar também que existem concepções morais com um escopo de abrangência maior do que concepções estritamente políticas. Concepções abrangentes, como o termo em inglês comprehensive nos lembra, devem ser entendidas como concepções completas ou "exaustivas" de bem: elas orientam a ação em todos, ou quase todos, os âmbitos de existência pessoal e, na maioria dos casos, procuram determinar a felicidade ou o sentido último da existência humana. Uma concepção política por sua vez é incompleta, ela não é capaz de nos dizer, por exemplo, no que devemos acreditar ou a qual Deus rezar, tampouco se devemos rezar. Dito de outro modo, ninguém poderia conduzir sua vida apenas por meio de uma concepção política de justiça, tanto quanto a identidade de alguém não pode ser determinada apenas por ser um(a) cidadão(ã) ${ }^{49}$

\section{Justiça ou Legitimidade?}

Aceitar que o objeto privilegiado de LP é a legitimidade e que Rawls não revisou a natureza do seu argumento moral não significa necessariamente aceitar que ambas as teorias - a teoria da justiça de TJ e a teoria da legitimidade de LP - sejam normativamente coerentes entre si. Mesmo contra suas próprias intenções, as exigências de legitimidade política impostas às concepções de justiça poderiam ser um obstáculo importante ao igualitarismo. $\mathrm{Na}$ verdade, algumas passagens parecem corroborar a visão de que LP compromete, em parte, o igualitarismo rawlsiano. Rawls reconhece explicitamente a compatibilidade de

48 Lembremos também que, tal como já havia sido argumentado em TJ, concepções de justiça são formuladas tendo em mente a estrutura institucional básica de uma sociedade e não a ação dos agentes.

49 Agradeço a Raissa Ventura por ter me levado a essa formulação. 
um amplo espectro de concepções de justiça, diferentes daquela que até então havia defendido, com as exigências da legitimidade liberal..$^{50} \mathrm{O}$ argumento pode ser formulado nos seguintes termos: tudo o que a legitimidade exige de uma concepção de justiça é que ela seja, em princípio, compatível com as liberdades individuais presentes nas cartas de direitos contemporâneos. Contudo, como sabemos, liberdades formais são empiricamente compatíveis com formas extremas de desigualdade material entre os cidadãos de uma mesma sociedade. Ou seja, o exercício legítimo da política, e do seu aparato coercitivo, não depende de uma concepção igualitária de justiça.

Se esse argumento estiver correto, então a teoria da legitimidade rawlsiana teria se aproximado de variedades conservadoras de liberalismo, especialmente o libertarianismo e o liberalismo clássico e, em nome da legitimidade, Rawls acabaria por tolerar formas de desigualdade originalmente incompatíveis com a justiça como equidade. Esse é um tipo de objeção, ao mesmo tempo, muito mais plausível que a tese da revisão e mais difícil de ser refutada. Contudo, acredito que também temos boas razões para rejeitá-la.

A teoria rawlsiana da legitimidade, como bem colocado por David Estlund, "não exige conformidade com uma concepção completa de justiça, uma vez que ela não especifica os termos da igualdade para além daquilo que é essencial do ponto de vista de uma constituição política". ${ }^{11}$ Isto é, uma teoria da legitimidade no sentido rawlsiano é elaborada tendo como objetivo o domínio do político e, para além desse tipo específico de relação, é plausível aceitarmos que uma sociedade possa ser estruturada das mais variadas formas. Segundo a interpretação proposta por Estlund, a qual subscrevo neste artigo, isso faz com que a justiça como equidade, e, particularmente, o Segundo Princípio, seja não apenas perfeitamente compatível com a legitimidade do poder político, mas também, do ponto de vista contratualista, a única forma justa de organizarmos a distribuição de recursos sociais valiosos entre agentes morais livres e iguais. Justiça e legitimidade não fazem exatamente as mesmas exigências normativas e não é exagero afirmarmos, portanto, "que os dois livros não tratam do mesmo assunto" ${ }^{52} \mathrm{O}$ objetivo em LP é mostrar como uma concepção de justiça contratualista não é opressiva e não que as exigências da justiça e da legitimidade demandam a mesma coisa.

A despeito de serem teorias concebidas para objetos diferentes, gostaria de terminar este artigo ressaltando um ponto importante da teoria da legitimidade 
rawlsiana: ela, por si só, possui consequências distributivas nada desprezíveis. Tais consequências são incompatíveis, por exemplo, com as duas variedades conservadoras mais importantes da tradição liberal: o libertarianismo e o liberalismo clássico. ${ }^{53} \mathrm{Na}$ medida em que qualquer teoria da justiça (e não apenas a justiça como equidade) necessariamente precisa atendê-las para garantir um uso não opressivo da autoridade política, não é descabido afirmar que, do ponto de vista da teoria da legitimidade rawlsiana, o poder de uma autoridade política fundada nas premissas dessas duas teorias deve ser considerado como moralmente ilegítimo.

Gostaria de indicar dois aspectos importantes de uma concepção política de justiça que nos permitem corroborar essa conclusão. O primeiro deles é a demanda (permanente) pela efetivação de direitos pessoais inscrita na ideia rawlsiana de constituição política. O segundo é a concepção de direito de propriedade defendida por Rawls. Atentar para esses dois aspectos significa reconhecer que a teoria da legitimidade rawlsiana aproxima-se muito mais de uma interpretação igualitária (ou até mesmo socialista) das condições materiais apropriadas para o exercício legítimo da autoridade política do que da tradição liberal clássica. Passemos brevemente por cada um desses pontos.

Em primeiro lugar, é importante notar que a "família" de concepções de justiça compatíveis com os critérios de legitimidade democrática imaginada por Rawls é bem mais restrita do que poderíamos imaginar à primeira vista. Para que uma concepção se qualifique, isto é, para que uma concepção atenda ao princípio liberal de legitimidade, ela precisa não somente assegurar a proteção de liberdades básicas individuais e proteger a igual dignidade de cada cidadão ou cidadã, algo que qualquer teoria vagamente liberal precisaria reconhecer, mas também responder de forma apropriada aos problemas de justiça distributiva básica que tornam essas liberdades efetivas. ${ }^{54}$ Algum critério de distribuição da riqueza social é necessário para que o exercício da coerção pública possa ser entendido como não opressivo. Vimos que, do ponto de vista da legitimidade, o Princípio de Diferença é apenas um critério possível entre outros. ${ }^{55}$ Contudo, isso significa que teorias da justiça que rejeitam a busca de padrões distributivos na medida em que seriam formas inaceitáveis de interferência na liberdade individual não podem atender a essa exigência. ${ }^{56}$

53 Ver Brennan e Tomasi (2012), para as premissas básicas do liberalismo clássico e do libertarianismo tal como estou entendo essas teorias neste trabalho.

54 Cf. LP (pp. 534-535).

55 Outros candidatos seriam, por exemplo, o princípio de utilidade média e o princípio de suficiência.

56 Cf. Hayek (1960, p. 87), Nozick (1974, pp. 155-160). 
Para além dessa exigência estrutural de princípios distributivos como uma condição de legitimidade, a teoria rawlsiana da legitimidade apresenta três consequências distributivas determinadas importantes. Uma é a ideia de um mínimo social incondicional como parte dos elementos constitucionais. Isto é, a criação legal de um patamar distributivo abaixo do qual nenhum cidadão deveria conduzir sua vida e ao qual todos e todas possuem acesso apenas pelo fato de ser um membro da sociedade. ${ }^{57} \mathrm{O}$ conceito de mínimo social pode encontrar diferentes expressões institucionais em diferentes sociedades, a depender das formas particulares da relação entre Estado e economia: serviços públicos universais, distribuição de renda em espécie etc. O ponto importante é que, não obstante a forma institucional adotada, a teoria da legitimidade rawlsiana estipula o direito incondicional a um patamar mínimo de segurança material como critério de validade de uma constituição. A razão para isso é que os direitos individuais, e o ideal de autorrespeito que eles protegem, perderia seu valor em contextos de privação material extrema. Essa exigência é abertamente incompatível com teorias libertarianas da autoridade política, segundo as quais toda forma de redistribuição de renda por meio de impostos é errada de um ponto de vista moral. ${ }^{58}$ Se seguirmos o argumento rawlsiano, portanto, somos obrigados a concluir que teorias libertarianas são explicitamente antiliberais. ${ }^{59}$

Outra forma importante de efetivação de direitos defendida em LP é a exigência de que a igualdade de direitos políticos tenha seu valor equitativo preservado. Isto é, que os arranjos institucionais protejam os agentes políticos da distribuição desigual de renda e riqueza. ${ }^{60}$ Efetivar direitos políticos implica, entre outras coisas, instituir esquemas redistributivos, como o financiamento público de campanhas, e regular o dinheiro utilizado na política. Tanto a ideia de que direitos à participação no autogoverno democrático sejam intrinsecamente tão importantes quanto as demais liberdades individuais, como a exigência

57 Ver LP (C VI, §5) e JCE (pp. 127-128). Weber (2013) apresenta uma boa discussão do papel de um "mínimo existencial" na justiça rawlsiana. Notemos que existe uma diferença importante entre o que Rawls chama de questões de justiça básica, de um lado, e a constitucionalização de demandas distributivas particulares, como direitos sociais ou um mínimo social, de outro. Rawls tem plena consciência de que boa parte do trabalho distributivo elementar em sociedades complexas vai além do que podemos, ou de que seria desejável, especificar em uma carta constitucional na forma de direitos individuais. Nesse sentido, o princípio de igualdade equitativa de oportunidades e o Princípio de Diferença, para ficarmos com a justiça como equidade, não constituem elementos constitucionais essenciais (cf. LP, pp. 264, 270-271). Agradeço a um comentário de Álvaro de Vita o esclarecimento desse ponto.

58 Cf. Nozick (1974, esp. pp. 153-155 e 167-169).

59 Cf. Freeman (2001). Vemos, portanto, que os critérios libertarianos não atenderiam demandas mínimas de razoabilidade. Se a minha interpretação está correta, então não podemos considerar reivindicações distributivas de teor libertariano como reivindicações razoáveis. Sandel comete o erro de utilizar o libertarianismo como um exemplo de desacordo moral a respeito de princípios de justiça distributiva em uma democracia (cf. 1994, pp. 1783-1784).

60 Ver LP (C VIII, § 12). A ideia, como vimos, já se encontrava em TJ (ver nota 10). 
de prerrogativas distributivas próprias a eles são contrárias ao liberalismo clássico. Para teóricos liberais como Friedrich Hayek, Milton Freedman e, mais recentemente, John Tomasi e Jason Brennan, as liberdades políticas são entendidas meramente em seu valor instrumental, como, por exemplo, a melhor forma de garantir a alternância do poder e não como uma forma de realizar um valor moral específico, como o ideal de autogoverno.

Finalmente, a noção de direito de propriedade assumido na teoria rawlsiana é incompatível com variedades tradicionais de liberalismo. É verdade que uma autoridade política legítima tem como parte de suas funções mais elementares proteger a propriedade de seus cidadãos - ou seja, um tipo de direito à propriedade faz parte dos elementos constitucionais elementares. Para Rawls, contudo, o que é moralmente relevante nesse direito é a proteção da propriedade pessoal, mas não, importa enfatizar, dos meios de produção. Dito em outras palavras, é um argumento relacionado mais à privacidade e ao desenvolvimento da personalidade de agentes autônomos do que ao aspecto econômico da propriedade. Isso quer dizer que nem o direito à propriedade dos recursos naturais nem dos meios de produção fazem parte dos critérios constitucionais do direito de propriedade.

Essa forma de conceber o direito de propriedade rejeita de modo categórico um dos dogmas centrais do liberalismo clássico, a saber, que a definição do direito de propriedade é anterior à justificação da autoridade política. Refiro-me à "definição", por oposição ao próprio direito, para ressaltar uma diferença importante entre o liberalismo clássico e o libertarianismo quanto a esse ponto. Libertarianos defendem que o próprio direito de propriedade é anterior à cooperação social e que a validade do princípio de propriedade-desi, normalmente associada aos "frutos do trabalho individual", independe de instituições políticas. Liberais clássicos, por sua vez, reconhecem que direitos e liberdades econômicas fundamentais - como o direito de propriedade dependem de regras e instituições políticas para serem exequíveis e, portanto, admitem certo grau de variação institucional. Contudo, a definição de liberdades econômicas no sentido liberal clássico abarca tanto as liberdades convencionais de ocupação e livre-iniciativa econômica como o pleno direito à propriedade produtiva - não aceitando, por exemplo, cláusulas como a da função social da propriedade. ${ }^{61} \mathrm{Ou}$ seja, nem o direito à propriedade dos recursos naturais nem o dos meios de produção fazem parte dos critérios constitucionais do direito de propriedade.

Se a minha leitura está correta, então, ao invés de representar um recuo dos comprometimentos igualitários, a teoria da legitimidade rawlsiana representa 
para as teorias morais contratualistas a possibilidade de igualitarismo em outros fronts de batalha dentro da filosofia política. Duas áreas que mereceriam uma maior atenção por parte de teóricos igualitários seriam, justamente, as condições distributivas de uma autoridade política legítima e as condições de justificação moral do direito de propriedade.

\section{Referências}

\section{Obras de Rawls}

JEP: "Justice as Fairness: Political not Metaphysical" [1985]. In: S. Freeman (ed.). John Rawls Collected Papers Cambridge Mass.: Harvard Press, 1999. pp. 388-414. JCE: "Justice as Fairness: a Restatement" (edited by Erin Kelly). Cambridge Mass.: Harvard Press, 2001.

LP: “O Liberalismo Político” (edição ampliada). São Paulo: Martins Fontes, [1996] 2011.

TJ: "Uma Teoria da Justiça”. 2a ed. São Paulo: Martins Fontes, [1971] 2009.

\section{Bibliografia complementar}

BARRY, B. "Theories of Justice (A Treatise on Social Justice vol. 1)". Berkeley: University of California Press, 1989.

915, 1995.

"John Rawls and the Search for Stability". Ethics, Vol. 105, Nr. 4, pp. 874-

BRENAN, J., TOMASI, J. “Classical Liberalism”. In: D. Estlund (ed.). The Oxford Handbook of Political Philosophy Oxford: Oxford Press, 2012. pp. 115-132.

COHEN, J. "Reflections on Rousseau: Autonomy and Democracy". Philosophy and Public Affairs, Vol. 15, Nr. 3, pp. 275-297, 1986.

COHEN, G. A. "Facts and Principles". Philosophy \& Public Affairs, Vol. 31, Nr. 3, pp. 211-245, 2003.

DARWALL, S. A Defense of the Kantian Interpretation. Ethics, Vol. 86, Nr. 2, pp. 164-170, 1976.

ELSTER, J. "Nuts and Bolts for the Social Sciences". Cambridge: Cambridge Press, 1989.

ESTLUND, D. "The Survival of Egalitarian Justice in John Rawls's Political Liberalism". The Journal of Political Philosophy, Vol. 4, Nr. 1, pp. 68-78, 1996.

FREEDMAN, M. "Capitalism and Freedom". Chicago: Chicago Press, 1968.

FREEMAN, S. "Illiberal Libertarians: Why Libertarianism Is Not a Liberal View". Philosophy and Public Affairs, Vol. 30, Nr. 2, pp. 105-151, 2001.

GAUS, G. "Is Public Reason a Normalization Project? Deep Diversity and Open Society". 2016. Disponível em http://www.gaus.biz/PublicReasonNormalization.pdf. (Acessado em $1^{\circ}$ de junho de 2016).

HAYEK, F. A. "The Constitution of Liberty". Chicago: Chicago Press, 1960.

HILL, T. E. Jr. "The Problem of Stability in Political Liberalism". Respect, Pluralism and Justice: Kantian Perspectives, Oxford, pp. 237-259, 2000. 
OKIN, S. M. "Political Liberalism [Review]". The American Political Science Review, Vol. 87, Nr. 4, pp. 1010-1011, 1993.

NOZICK, R. "Anarchy, State and Utopia". New York: Basic Book, 1974.

PETRONI, L. “Temos o dever de tolerar?". Revista Brasileira de Ciência Política, Nr.

15, pp. 95-125, 2014. Disponível em http://www.scielo.br/pdf/rbcpol/n15/0103-3352rbcpol-15-00095.pdf. (Acessado em $1^{\circ}$ de junho de 2016).

RORTY, R. "The Priority of Democracy to Philosophy". In: Objectivity, Relativism and Truth (Philosophical Papers vol. 1). Cambridge: Cambridge Press, 1990. pp. 174-196. SANDEL, M. "Political Liberalism (Review)". Harvard Law Review, Vol. 107, Nr. 7, pp. 1765-1794, 1994.

SCANLON, T. "Contractualism and Utilitarianism". In: The Difficulty of Tolerance. Cambridge: Cambridge Press, 2003. pp. 124-150.

SHKLAR, J. "The Liberalism of Fear". In: N. Rosemblum (ed.). Liberalism and the Moral Life Cambridge Mass.: Harvard Press, 1989. pp. 21-38.

TAYLOR, C. "The Politics of Recognition". In: A. Gutmann (ed.). Multiculturalism. New Jersey: Princeton Press, 1994. pp. 25-73.

TOMASI, M. "Free Market Fairness". New Jersey: Princeton Press, 2012.

VINCENT, A. "The Nature of Political Theory". Oxford: Oxford Press, 2004. VITA, A. "A justiça igualitária e seus críticos". São Paulo: Martins Fontes, 2007. . "Sociedade Democrática e Tolerância Liberal". Revista Novos Estudos Cebrap, Vol. 84, pp. 61-81, 2009. Disponível em http://www.scielo.br/pdf/nec/n84/n84a05.pdf. (Acessado em $1^{\circ}$ de junho de 2016).

WALDRON, J. "John Rawls and the Social Minimum". Journal of Applied Philosophy, Vol. 3, Nr. 1, pp. 21-33, 1986.

"Political Political Theory". The Journal of Political Philosophy, Vol. 21, Nr.

2, pp. 1-23, 2013.

WALZER, M. “'Spheres of Justice': an Exchange”. New York Review of Books, July 21, 1983. Disponível em http://www.nybooks.com/articles/1983/07/21/spheres-ofjustice-an-exchange/. (Acessado em $1^{\circ}$ de junho de 2016).

WEBER, T. "A ideia de um 'mínimo existencial' de J. Rawls". Kriterion: Revista de Filosofia, Vol. 54, Nr. 127, pp. 197-210, 2013. Disponível em http://www.scielo.br/ scielo.php?script=sci_arttext\&pid=S0100-512X2013000100011. (Acessado em $1^{\circ} \mathrm{de}$ junho de 2016).

WEITHMAN, P. J. "Why Political Liberalism? On John Rawls's Political Turn". Oxford: Oxford Press, 2011.

WILLIAMS, B. “A Fair State”. London Review of Books, Vol. 15, Nr. 9, pp. 7-8, May 1993.

."The Liberalism of Fear". In: In The Beginning Was The Deed: Realism and Moralism in Political Argument, New Jersey: Princeton Press, 2005. pp. 52-61.

YOUNG, I. M. "Rawls's Political Liberalism". The Journal of Political Philosophy, Vol. 3, Nr. 2, pp. 181-190, 1995. 